Revista de Estudios Histórico-Jurídicos

[Sección derecho romano]

XLII (Valparaíso, Chile, 2020)

[pp. 145- 165]

\title{
ADTEMPTATA PUDICITIA: EL ACOSO CALLEJERO EN LA EXPERIENCIA JURÍDICA ROMANA
}

[ "Adtemptata pudicitia”: Street Harassment in the Roman Legal Experience]

\author{
Benjamín Musso Arratia* \\ Universidad del Desarrollo, Chile
}

RESUMEN

En este trabajo se analiza la regulación edictal de los acosos callejeros en la República romana, con especial atención en los sujetos pasivos del ilícito - materfamilias y jóvenes praetextati-y la forma de comisión -comitem abducere, appellare y adsectari-. Además, se propone que el edicto no se restringe a materfamilias de altas clases sociales.

Palabras clave

Adtemptata pudicitia - materfamilias - comitem abducere -appellare - adsectari - iniuria.
AbSTRACT

This work analyzes the Edictal regulation of Street Harassment in the Roman Republic, with special attention to the victims of the illicit - materfamilias and praetextati - and the form of commission comitem abducere, appellare and adsectari-. Furthermore, it is proposed that the edict is not restricted to materfamilias of high social classes.

\section{KeY WordS}

Adtemptata pudicitia - materfamilias - comitem abducere -appellare - adsectari - iniuria.

ReCibido el 30 de abril de 2020 y ACEPTADO el 16 de junio de 2020

\section{A MODO DE INTRODUCCIÓN}

En 2018, algunas municipalidades de Santiago de Chile comenzaron a dictar ordenanzas locales contra los acosos callejeros que no dejaron indiferentes a la opinión pública, recibiendo buena acogida por una parte de la población y levan-

*Abogado. Licenciado en Ciencias Jurídicas, Universidad del Desarrollo. Magister en Ciencia Jurídica, Pontificia Universidad Católica de Chile. Candidato a Doctor en Derecho, Pontificia Universidad Católica de Chile. Profesor de Derecho Romano, Universidad del Desarrollo. Correo electrónico: bmusso@uc.cl. 
tando críticas de otros sectores ${ }^{1}$. En general, ellas definen el acoso callejero como "toda práctica de connotación sexual no consentida cometida en contra de una o más personas en espacios públicos, o de acceso público, tales como silbidos, comentarios o gestos obscenos, piropos, persecución a pie o en vehiculo, arrinconamiento, captación de imágenes, videos o cualquier otro registro audiovisual'.

La ratio legis tras estas ordenanzas se funda en la necesidad de asegurar a todas las personas un tránsito libre de violencia y de actos que lesionen la dignidad humana, la necesidad de contribuir a erradicar las prácticas de acoso callejero y la importancia de reconocer dicho acoso callejero como un tipo de violencia, estableciéndose multas de hasta 5 UTM, sin perjuicio de las penas por el delito de injuria, si procediere ${ }^{2}$.

En mayo del mismo año, en la comuna de Las Condes, se cursó la primera multa contra un verdulero que le dijo a una transeúnte "Coma más ensalada para que conserve su linda silueta”. La medida fue altamente criticada tildándola de totalitaria, exagerada y orwelliana ${ }^{3}$. Sin embargo, ella ha sido replicada en cada vez más comunas de nuestro país.

Luego, en 2019, la Ley 21.153 modificó el Código Penal, incorporando un artículo 494 ter, que tipifica el delito de acoso sexual como "el que realizare, en lugares públicos o de libre acceso público, y sin mediar el consentimiento de la víctima, un acto de significación sexual capaz de provocar una situación objetivamente intimidatoria, hostil o humillante, y que no constituya una falta o delito al que se imponga una pena más grave", estableciendo dos supuestos distintos de comisión del ilícito: actos de carácter verbal o ejecutados por medio de gestos o conductas consistentes en acercamientos o persecuciones, o actos de exhibicionismo obsceno o de contenido sexual explícito, estableciéndose multas en ambos casos y en el último arriesgando, además, pena de prisión en sus grados medio a máximo ${ }^{4}$.

Hoy, los debates giran en torno a dilucidar si es el derecho el llamado a regular estas conductas y sancionarlas, por lo que resulta siempre útil mirar hacia Roma y la evolución de sus instituciones jurídicas para tratar de dar con una respuesta. Se dice que la historia es cíclica, y lo cierto es que en la experiencia jurídica romana encontramos casos de acoso callejero, que recibieron regulación pretoria

${ }^{1}$ V. gr. https://www.emol.com/noticias/Nacional/2018/11/20/927988/Acoso-callejeroen-Santiago-Concejala-pide-que-se-ponga-el-tema-sobre-la-tabla.html [Fecha de consulta: 28 de abril de 2020]

${ }^{2}$ V. gr. Decreto 2959-2018, de la Municipalidad de Las Condes.

${ }^{3} \mathrm{~V}$.gr. https://www.cooperativa.cl/noticias/pais/mujer/concejales-quieren-echar-atras-laordenanza-anti-piropos-de-joaquin/2018-08-24/160113.html [Fecha de consulta: 28 de abril de 2020]

${ }^{4}$ Art. 494 ter del Código Penal: "Comete acoso sexual el que realizare, en lugares públicos $o$ de libre acceso público, y sin mediar el consentimiento de la víctima, un acto de significación sexual capaz de provocar una situación objetivamente intimidatoria, hostil o humillante, y que no constituya una falta o delito al que se imponga una pena más grave, que consistiere en: 1. Actos de carácter verbal o ejecutados por medio de gestos. En este caso se impondrá una multa de una a tres unidades tributarias mensuales. 2. Conductas consistentes en acercamientos o persecuciones, o actos de exhibicionismo obsceno o de contenido sexual explícito. En cualquiera de estos casos se impondrá la pena de prisión en su grado medio a máximo y multa de cinco a diez unidades tributarias mensuales". 
en el edicto de adtemptata pudicitia, una forma especial de iniuria, cuya somera revisión proponemos.

\section{INJURIAS EDICTALES Y EDICTO DE ADTEMPTATA PUDICITIA}

Durante el curso de la historia, la iniuria transita de la esfera de la lesión física a las lesiones contra el honor ${ }^{5}$, despojándose en cierta medida de su contenido

${ }^{5}$ Vid. Voigt, Moritz, Die XII Tafeln Geschichte und System des Civil- und Criminal-Rechtes, wie -Processes der XII Tafeln nebst deren Fragmenten (Leipzig, Verlag von A. G. Liebeskind, 1883), II, pp. 519 ss.; IHeRING, Rudolph, Actio injuriarum. Des lésions injurieuses en droit romain [et en droit français] (Paris, Chevalier-Marescq \& Cie. Éditeurs, 1888), pp. 1 ss.; Mommsen, Theodor, Römischen Strafrecht (Leipzig, Verlag von Duncker \& Humblot, 1899), IV, pp. 784 ss.; Huvelin, Paul, La notion de l'iniuria dans le très ancien droit romain (Lyon, A. Rey, imprimeur-éditeur, 1903), pp. 6 ss.; BINDING, Karl, Rechtsvergleichende Vermutungen zu membrum ruptum, os fractum und injuria der Lex XII Tabularum, en ZSS., 40/1 (Graz, 1919), pp. 106-112; APPLETON, Charles, Notre enseignement du droit romain, ses ennemis et ses défauts, en COLLINET, Paul; DE VISSCHER, Fernand (eds), Mélanges de droit romain dédiés a Georges Cornil (París, Sirey, 1926), pp. 43-79; LuZZATTO, Giuseppe, Per un’ipoesi sulle origini e la natura delle obbligazioni romane (Milano, Giuffrè, 1934), pp. 173 ss.; Pugliese, Giovanni, Studi sull'iniuria (Milano, Giuffrè, 1940); Di Paola, Santi, la genesi storica del delitto di 'iniuria', en Annali del Seminario Giuridico dell'Università di Catania, 1 (Napoli, 1946-1947), pp. 265 ss.; SIMON, Dietrich, Begriff und Tatbestand der 'iniuria' im altrömischen Recht, en ZSS., 82 (Weimar, 1965), pp. 132 ss.; DA NobreGA, Vandick, La "iniuria" dans la loi des XII tables, en Romanitas, 8 (1967), pp. 250 ss.; BIRKS, Peter, The early history of iniuria, en TR., 37 (Groningen - Bruxelles - La Haye, 1969), pp. 163 ss.; VON LÜBTOw, Ulrich, Zum römischen Injurienrecht, en Labeo, 15 (Napoli, 1969), pp. 131 ss.; WitTMann, Roland, Die Körperverletzung an freien im klassischen römischen Recht (München, Beck, 1972), pp. 3 ss.; Watson, Alan, Personal Injuries in the XII Tables, en TR., 43 (Groningen - Bruxelles - La Haye, 1975), pp. 213 ss.; ManfredinI, Arrigo, Contributi allo studio dell' "iniuria" in età repubblicana (Milano, Giuffrè, 1977), pp. 15 ss.; Plescia, Joseph, The development of 'iniuria', en Labeo, 23 (Napoli, 1977), pp. 271 ss.; Bravo Bosch, María José, Sobre el origen histórico del edicto de convicio, en Revista General de Derecho Romano, 23 (Madrid, 1983), pp. 1 ss.; Pólay, Elemér, Iniuria types in Roman law (Budapest, Akadémiai Kiadó, 1986), pp. 16 ss.; RodGer, Alan, Introducing “iniuria”, en TR., 59 (Groningen - Bruxelles - La Haye, 1991), pp. 1 ss.; Zimmermann, Reinhard, The Law of Obligations. Roman Foundations of the Civilian Tradition (Oxford, Oxford University Press, 1996), pp. 1050 ss.; Hagemann, Matthias, Iniuria. Von den XII-Tafeln bis zur justinianischen Kodifikation (Köln - Weimar - Wien, Böhlau, 1998), pp. 9 ss.; CURSI, Maria Floriana, Iniuria cum damno. Antigiuridicità e colpevolezza nella storia del danno aquiliano (Milano, Giuffrè, 2002), pp. 221 ss.; GUERRERo Lebrón, Macarena, La injuria indirecta en derecho romano (Madrid, Dykinson, 2005), pp. 27-71; BRAVo BosCH, María José, La injuria verbal colectiva (Madrid, Dykinson, 2007), pp. 25 ss.; LA MISMA, A propósito de la protección del honor de la persona, en Revista Jurídica Universidad Autónoma de Madrid, 16 (Madrid, 2007), pp. 29 ss.; CuRsI, Maria Floriana, Danno e responsabilità extracontratratuale nella storia del diritto privato (Napoli, Jovene, 2010), pp. 7 ss.; GuZMÁn Brito, Alejandro, Derecho privado romano $^{2}$ (1996, Santiago, Legal Publishing-Thomson Reuters, 2013), II, pp. 302-303; CaRvajal Ramírez, Patricio Ignacio, La función de la pena por la 'iniuria' en la Ley de las XII Tablas, en REHJ., 35 (2013), pp. 151 ss; ÉL MISMO, La iniuria en las XII tablas. Cuestiones filológicas, históricas y dogmáticas, en Mondaca Miranda, Alexis; Aedo Barrena, Cristián (eds.), Nuevos horizontes del derecho privado (Santiago de Chile, Librotecnia, 2013); MiglietTA, Massimo, Le norme di diritto criminale, en CURSI, Maria Floriana (a cura di), XII Tabulae. Testo e commento (Nápoles, Edizioni Scientifiche Italiane, 2018), II, pp. 488 ss. 
decenviral original ${ }^{6}$. Para nosotros, dos son los factores para ello: la dictación y posterior interpretación jurisprudencial de la lex Aquilia y la intervención edictal del pretor en el contexto socioeconómico del siglo II a. C. Para estos efectos, será relevante este segundo factor ${ }^{7}$.

Hacia finales del siglo III a. C. ${ }^{8}$ el pretor dará un edicto de injurias para las

${ }^{6}$ Africano, según da cuenta Gelio, se refiere a un momento en que, de facto, las normas decenvirales de iniuria han caído en desuso "(Noctes Atticae 20, 1, 37-38.- Quod edictum autem praetorum de aestimandis iniuriis probabilius esse existimas nolo hoc ignores hanc quoque ipsam talionem ad aestimationem iudicis redigi necessario solitam. (38) Nam si reus, qui depecisci noluerat, iudici talionem imperanti non parebat, aestimata lite iudex hominem pecuniae damnabat, atque ita, si reo et pactio gravis et acerba talio visa fuerat, severitas legis ad pecuniae multam redibat)", posterior a lo cual ocurriría según PUGLIESE, Giovanni, Studi, cit. (n. 5), p. 81, la unificación del término iniuria como lesión corporal, luego de lo cual los pretores, siguiendo un senadoconsulto del siglo III a. C. que habría extendido -sin necesidad de edicto- el régimen de estimación de penas que ya se venían dando respecto al membrum ruptum a los demás casos decenvirales, so pretexto de la devaluación del as. Luego, a través del edicto se darán recuperatores para casos tipificados de injuria - pulsationes e infamatio- (NA. 20, 1, 13.- Propterea inquit praetores postea hanc abolscere et relinqui consuerunt iniuriisque aestumandis recuperatores se daturos adixerunt), extendiéndose finalmente, merced de la jurisprudencia, a la idea de iniuria-contumelia labeoniana. Vid. Manfredini, Arrigo, Contributi, cit. (n. 5), pp. 152-153. Lleva razón CuRsi, Maria Floriana, Iniuria cum damno, cit. (n. 5), p. 263, cuando establece que el vuelco en la noción de iniuria ya se observa en la comedia plautina (Poenulus 1337-1338), es decir, al menos un siglo antes de la idea dada por Labeón. Sin perjuicio de cómo se dio la abstracción de la injuria, lo relevante es que ella abarcó, en tiempos post decenvirales, situaciones adicionales a las lesiones físicas, por lo que su concepción se vio ampliada, no reemplazada. Vid. Voigt, Moritz, Die XII, cit. (n. 5), pp. 516-522; Witman, Roland, Die Körperverletzung, cit. (n. 5), p. 23; CuRSI, Maria Floriana, Iniuria cum damno, cit (n. 5), p. 273.

${ }^{7}$ Plecia, Joseph, The development, cit. (n. 5), p. 281, lo denomina como un periodo de la revolución romana. Para conocer los cambios socioeconómicos del siglo III a. C., vid. DE Martino, Francesco, Storia economica di Roma antica (Florencia, La Nuova Italia Editrice, 1979), pp. 69 ss.; FORSYTHE, Gary, A Critical History of Early Rome (Berkeley, University of California Press, 2005), pp. 268 ss.; ScheILDel, Walter et al., The Cambridge Companion to the Roman Economy (Londres, Cambridge University Press, 2012), pp. 487 ss.; Amunátegui Perelló, Carlos, Market Economic in the Middle Republic, en ZSS., 101 (Weimar, 2015), pp. 452-458.

${ }^{8}$ Vid. Watson, Alan, cit. (n. 5), pp. 1 y ss.; Birks, Peter, cit. (n. 5), p. 194 ss., para quien éste debió haber sido, en todo caso, posterior a la lex Aquilia; PlesCiA, Joseph, cit. (n. 5), p. 282, concuerda con la fecha aproximada de Asinaria de Plauto; Cursi, Maria Floriana, Iniuria cum damno, cit. (n. 5), p. 263 lo fija a finales de la centuria o incluso, comienzos del siglo II a.C. Sin embargo, la fecha del edicto de injurias no es pacífica. Algunos lo fijan un siglo después, v. gr., Santa Cruz, José; D'Ors Álvaro, A propósito de los edictos especiales 'De iniuriis', en AHDE., 49 (Madrid, 1979) p. 655, limitándolos eso sí hasta un momento anterior a la lex Aebutia; Bravo Bosch, María José, La injuria, cit. (n. 5), p. 70; Perozzi, Silvio, Istituzioni di dirito romano, en Capogrossi, Luigi (ed.), Istituzioni di diritto romano. Ristampa dell'edizione del $1928^{2}$ (1928, reimp., Roma, Athenaeum, 1963), II, p. 338 quien, a su turno, lo fecha luego del año 130 a. C., es decir, posterior a la lex Aebutia. De lo que no puede dudarse es su anterioridad a la lex Cornelia de iniuriis. Vid. Schulz, Fritz, Derecho romano clásico (trad. cast., Barcelona, Bosch, 1960), p. 572, teniendo en consideración que, como fuere, hubo de ser durante la República. También Von LÜBTOw, Ulrich, Zum, cit. (n. 5), p. 155. Nosotros, concordando con Birks, vemos la abstracción de la injuria comenzando con la lex Aquilia, en un periodo pre-edictal, que pudo extenderse hasta principios del siglo II a. C., por lo que los edictos de injuria debieron aparecer entre este periodo y uno cercano a la lex Aebutia, por la mención hecha los recuperatores 
lesiones personales estableciendo una actio iniuriarum aestimatoria $a^{9}$ conocido como edictum generale de iniuriis aestimandis ${ }^{10} \mathrm{y}$ al poco andar ${ }^{11}$ extenderá su protección a las ofensas contra el honor, el pudor y la dignidad a través de algunos edictos especiales ${ }^{12}$, entre ellos, el edicto de adtemptata pudicitia. Según la reconstrucción de Lenel ${ }^{13}$, el texto sería "Si quis matrifamilias aut praetextato praetextataeve comitem abduxisse sive quis eum eamve adversus bonos mores appellasse adsectatusve esse dicetur", tomando como base para ello I. 4, 4, 114, fundada a su vez en Gai. 3, $220^{15}$. De estos textos es dable colegir como características

por Aulo Gelio (NA. 20,1,13), consolidándose esta abstracción en la idea de iniuria-contumelia labeoniana, a finales del siglo I a. C. o inicios del siglo I d. C.

'Sobre esta acción, vid. FioRI, Roberto, Le formule dell'actio iniuriarum, en Acta Universitatis Szegediensis - Acta juridica et politica, 65 (Szeged, 2004), pp. 147-156.

${ }^{10} \mathrm{Su}$ existencia es debatida en la doctrina. Nosotros pensamos que efectivamente existió como respuesta pretoria al desuso del talión dado el contexto socioeconómico de Roma, pero no es el momento de hacerse cargo de ello. Para conocer sobre esta discusión vid. BRAvo BosCH, María José, La injuria, cit. (n. 5), pp. 63-68, quien resume las principales ideas de la doctrina.

${ }^{11}$ Según se ha establecido por parte de la doctrina corresponderían al último tercio del siglo II a. C. Así, tras el edictum generale vino el edicto de convicio, luego el de adtemptata pudicitia y finalmente el edicto ne quid infamandi causa fiat. Vid., por todos, VON LÜвTOw, Ulrich, Zum, cit. (n. 5), pp. 156 ss., quien recurre al orden dado por el edicto perpetuo de Salvio Juliano. Como bien apunta De Lapuerta, el único dato preciso para datar el edicto de adtemptata pudicitia guarda relación con la lex Scatinia (220 a. C. aproximadamente), debiendo ser posterior a ella, por cuanto tiene una penalidad más leve que la establecida en la ley. Cantarella lo fecha en el año 193 a. C, tomando como base el Curculio de Plauto (Curculio 35-38) donde se alude a nuptae, viudae y virgines lo que tiene similitud con los sujetos pasivos del edicto. Vid. DE LAPUERTA MONTOYa, Dora, Estudio sobre el edictum de adtemptata pudicitia (Madrid, Tirant Lo Blanch, 1999), p. 52; Cantarella, Eva, Según natura. La bisexualidad en el mundo antiguo (1988, Madrid, trad. cast., Akai, 1991), pp. 156-157.

${ }^{12}$ Para evitar extendernos no trataremos los demás edictos especiales. Si se quiere saber de ellos, véase Manfredini, Arrigo, La diffamazione verbale nel diritto romano (Milano, Giuffrè, 1979), pp. 49 ss.; Daube, David, Ne quid infamandi causa fiat, en Collected Studies in Roman Law (Frankfurt, V. Klostermann, 1991), 2 vols.; Bravo Bosch, María José, La iniuria, cit. (n. 5), pp. 59 ss.; La misma, A propósito de la protección del honor de la persona, en Revista Jurídica Universidad Autónoma de Madrid, 16/2 (Madrid, 2007), pp. 29-54.

${ }^{13}$ Lenel, Otto, Das Edictum Perpetuum. Ein Versuch zu seiner Wiederherstellung ${ }^{3}$ (1883, Lepizig, Tauchnitz, 1927), p. 400.

${ }^{14}$ I. 4, 4, 1: "Iniuria autem committitur non solum, cum quis pugno puta aut fustibus caesus vel etiam verberatus erit, sed etiam si cui convicium factum fuerit, sive cuius bona quasi debitoris possessa fuerint ab eo, qui intellegebat nibil eum sibi debere, vel si quis ad infamiam alicuius libellum aut carmen scripserit composuerit ediderit dolove malo fecerit, quo quid eorum fieret, sive quis matrem familias aut praetextatum praetextatamve adsectatus fuerit, sive cuius pudicitia attemptata esse dicetur: et denique aliis pluribus modis admitti iniuriam manifestum est" ("Cometemos injuria no sólo cuando alguno hubiere sido golpeado con el puño o bastón o azotado, sino también si se hubiere promovido a alguien un escándalo, o si los bienes de uno hubieren sido poseídos como de un deudor, por aquel que sabía que nada se le debía; o si alguien para infamia de otro hubiere escrito, compuesto, o publicado algún libelo o versos, o procurado con dolo malo que algo de esto se hiciera; o si alguno hubiere seguido a una madre de familia, a un joven o a una joven; o si se dijese que se habla atentado al pudor de alguien; y finalmente, es evidente que de otras muchas maneras se comete injuria").

${ }^{15}$ Gai. 3, 220: Iniuria autem committitur non solum, cum quis pugno puta aut fuste percussus vel etiam verberatus erit, sed etiam si cui convicium factum fuerit, sive quis bona alicuius quasi 
del ilícito edictal: i) la indeterminación del sujeto activo, pudiendo tratarse por igual de un ciudadano, un peregrino, un patricio o un plebeyo ${ }^{16}$; ii) la calificación de los sujetos pasivos, siendo una materfamilias o de jóvenes, de cualquier sexo, que lleven la toga praetexta; iii) las formas típicas comisivas, correspondiendo a comitem abducere, apellare y adsectari, sobre los que volveremos, y iv) el lugar de ejecución, tratándose de actos que sólo pueden darse en público ${ }^{17}$. Todas estas características podrían tentarnos a buscar una sanción pre-edictal a estas conductas de acoso en la regulación decenviral, la cual, empero, no está contemplada en T. $8,2-4^{18}$, referentes a la iniuria ${ }^{19}$. Tampoco lo sería occentare $^{20}$, pues en ella -junto al carmen malum- lo que realmente sanciona es el recurso de la magia ${ }^{21}$.

debitoris sciens eum nibil sibi debere proscripserit, sive quis ad infamiam alicuius libellum aut carmen scripserit, sive quis matrem familias aut praetextatum adsectatus fuerit, et denique aliis pluribus modis ("Hay injuria no sólo cuando se pega a alguien con el puño o con el palo, o cuando se le azota, sino también cuando se le afrenta públicamente, ya diciendo a voces que es insolvente, a pesar de saber que no se debe nada, ya escribiendo un libelo o una copla infamatoria, ya asediando a una mujer honrada o a un joven, y, en fin, de otros muchos modos").

${ }^{16}$ Las injurias edictales, como hemos podido observar (n. 6 y n. 8), se desarrollaron a partir de su regulación decenviral, y como tal, han de responder a una voluntad isonómica, existente en el derecho romano ya desde la segunda cesión plebeya en el siglo $\mathrm{V}$ a. C, reflejada en las XII Tablas, la lex Canuleia y las leges Liciniae Sextiae. Vid. Amunátegui Perelló, Carlos, Historia social, política y jurídica de Roma (Santiago de Chile, Abeledo Perrot, 2011), pp. 32 ss., por lo que no sería dable pensar que, tres siglos después, exista una involución a este respecto considerándose la diferencia entre patricios y plebeyos al momento de ser considerado titular de la acción - y consecuencialmente víctima- de injurias. Por lo demás, las fuentes no establecen esta distinción. En lo que respecta a los peregrinos, desde las leges Liciniae Sextiae con la creación del pretor peregrino éstos han pasado a formar parte de la realidad jurídica de Roma. De hecho, la propia existencia de recuperatores (NA. 20,1,13) en el desarrollo de la injuria es testimonio de ello, por cuanto suele vinculárseles al arbitraje internacional. KASER, Max, Das römische zivilprozessrecht (München, C. H. Beck'sche verlagsbuchhandlung, 1996) pp. 197 ss.; idea que se refuerza en Poenulus (Poenulus 1337-1338) donde los actores por injurias son cartagineses y no romanos.

${ }^{17}$ De Lapuerta Montoya, Dora, El elemento subjetivo en el edictum de adtemptata pudicitia: La contravención de los boni mores como requisito esencial para la existencia de responsabilidad, en Anuario da Facultade Dereito da Universidade da Coruña, 2 (A Coruña, 1998), p. 239.

${ }^{18}$ T. 8, 2-4.- (2) Si membrum rup [s] it, ni cum eo pacit, talio esto. (3) manus fustive os fregerit libero, CCC, si servo, CL poenam subito. (4) si iniuriam [alteri] faxsit, viginti quinque poenae sunto, en FIRA., Leges, pp. 53-54. En cuanto a los problemas de transmisión textual y reconstrucción de estas tablas, vid. Carvajal RamíreZ, Patricio Ignacio, Apuntes sobre la injuria en las XII Tablas y su transmisión textual, en Revista Chilena de Derecho, 40, 2 (Santiago, 2013), pp. 727 ss.

${ }^{19}$ T. 8, 1.- "(a) Qui malum carmen incantassit... (b) nostrae XII tab. cum perpaucas res capite sanxissent, in his hanc quoque sanciendam putauerunt: si quis occentauisset siue carmen condidisset, quod infamiam faceret flagitiumue alteri.”, en FIRA., Leges, p. 51.

${ }^{20}$ Vid. Bravo Bosch, María José, La iniuria, cit. (n. 5), p. 35; Escutia Romero, Raquel, La difamación pública en derecho romano, en Revista Juridica Universidad Autónoma de Madrid, 22/2 (Madrid, 2010), p. 91; Miglietta, Massimo, Le norme, cit. (n. 5), p. 490.

${ }^{21}$ Aun con una aparente mayor cercanía a los atentados impúdicos, no vemos en occentare indicios claros, pues de las noticias que tenemos de este delito no podemos concluir que exista una situación análoga a la adtemptata pudicitia. Si bien occentare se ha entendido como componer canciones infamantes y según D’Ors guarda relación con ofensas proferidas en público, se sanciona, al decir de Cicerón, con la pena capital. Fuera de lo desmedido que ello parece (¿Acaso los romanos por unos cuantos insultos impúdicos proferidos fuera del ámbito privado habrían 
Así, la adtemptata pudicitia es propia de su época, donde el talión ha caído en desuso y en la cual los cambios socioeconómicos han permitido la proliferación de condenas aestimatorias ${ }^{22}$.

Al decir de Birks, Gayo (Gai. 3, 220) recurre a la fórmula "non solum [... sed etiam” al delimitar la injuria por tratarse en sí de una enumeración incomoda ${ }^{23}$. Sin pretender entrar en el asunto de qué debe entenderse por iniuria ${ }^{24}$, destacamos del pasaje que éste emplea una clasificación binaria: se injuria por golpe o por afrentas. Sin embargo, otras fuentes recurren a una triple clasificación, donde la adtemptata pudicitia a nuestro entender cobra aún más valor. Así queda de manifiesto en la Retórica a Herenio, la cual si bien comienza diciendo en Ad. H. 2, 26, 41 "iniuria ese nullam nisi quaeex pulsatione aut convicio constet" concluye en Ad.

sancionado al ofensor con la muerte y, por ejemplo, en el caso del mebrum ruptum u os fractum habrían impuesto el talión?) la sanción nos revela que las noticias sobre estos acosos que tenían los juristas clásicos responden a su tiempo, donde las supersticiones se han perdido; conclusión que resulta de la copla que hace el Arpinate con carmen malum, es decir, con recitar fórmulas mágicas destinadas a provocar un daño, incluso la muerte, de la víctima del conjuro. Por ende, lo que se estaría sancionando no es la infamia en sí, sino el recurso de la magia, que a juicio de Miglietta, hiere gravemente la paz social, incluso la pax deorum, lo que habría llevado a su drástica sanción. Vid. Huvelin, Paul, La notion, cit. (n. 5) pp. 18 ss.; D’Ors, Álvaro, Sobre el hechizo de cosechas en las Doce Tablas, en Gutiérrez Estévez, Manuel et al., Homenaje a Julio Caro Baroja (Madrid, Centro de Investigaciones Sociológicas, 1978), pp. 100 ss.; MANFrEDINI, Arrigo, La diffamazione, cit. (n. 12) pp. 1-49; Bravo BosCH, María José, La iniuria, cit. (n. 5), p. 40; Miglietta, Massimo, Le norme, cit. (n. 5), pp. 485 ss.

${ }^{22} \mathrm{La}$ coyuntura socioeconómica hizo de los siglos III y II a. C. el momento ideal para la proliferación de condenas aestimatorias. Sucintamente, un siglo antes, Roma se volvió imperialista, haciendo del Mediterráneo un Mare Nostrum. Tal hegemonía mediterránea produjo un cambio en el sistema económico romano, transitando de una economía agraria con mercado a una economía de mercado y de una economía metalizada a una monetizada. Véase AMUNÁTEGUI Perelló, Carlos, Historia, cit. (n. 16), pp. 44-69. El mercado permea incluso en la condemnatio permitiendo el tránsito de penas rígidas a condenas variables, como ocurre con las injurias - de facto en un momento pre-edictal y luego de iure con los edictos de iniuriis aestimandis, y con la lex Aquilia, que en su redacción original incorpora la variación del valor de mercado. CANNATA, Carlo Augusto, Sul texto della Lex Aquilia e la sua portata originaria, en VACCA, Letizia (ed.), Carlo Augusto Cannata. Scriti Scelti, (Turín, G. Giappichelli Editore, 2012), II, pp. 169-170. Si nos damos cuenta iniuria y damno iniuria datum son delitos civiles, lo cual no es accidental. Recordemos que en este periodo para las injurias se habían dado recuperatores, puesto que el desarrollo económico hizo de la ciudad pasto de crisis intestinas. Durante el siglo III a. C., Roma tuvo 46 eventos bélicos, quince dentro de Italia o entre romanos, las guerras púnicas, cuatro guerras civiles y tres guerras serviles. En ese contexto los recuperatores no sólo acusan un momento de ferviente comercio internacional, sino que, además, cumplen una función de restablecimiento del orden post conflictos sociales, remedio extendido luego a los negocios jurídicos, primero, con la injuria. En ese contexto, no es raro que existan delitos -lesiones y daños- que hayan sido reforzados, con la lex Aquilia para una nueva regulación de los daños y con la reelaboración de las injurias para las lesiones físicas y morales, ambos delitos de gran connotación en un contexto de crisis social. BIRKS, Peter, The early, cit. (n. 5), pp. 197-200. En tiempos de Sila veremos el mismo recurso con la lex Cornelia de iniuriis y la lex Cornelia de sicariis et veneficiis. Además, y aun cuando no regule un delito, mencionemos que la lex Hortensia responde a este periodo de convulsiones internas.

${ }^{23}$ Birks, Peter, The early, cit. (n. 5), p. 173.

${ }^{24}$ Por todos, Cursi, Maria Floriana, Iniuria cum damno, cit. (n. 5), pp. 222 ss. 
H. 4, 25, 35 señalando "iniuriae sunt quae aut pulsatione corpus aut convicio aures aut aliqua turpitudine vitam cuiuspiam violant". Luego, lo mismo ocurre con Ulpiano, quien en el libro 56 de sus comentarios al Edicto, D. 47,10,1,2 señala "omnenique inuriam aut in corpus inferri, aut ad dignitatem, aut ad infamiam pertinere; in corpus fit, quum quis pulsatur, ad dignitatem, quum comes matronae abducitur, ad infamiam, quum pudicitia attentatur".

De este modo, adtemptata pudicitia no entra en estrictamente en la esfera de los atentados al honor, sino contra la dignidad, ergo, no es una forma de injuria general sino una forma lesiva propia, sin perjuicio de relacionarse con la injuria, ciertamente, cuando no hay realmente atentado impúdico en el apellare, como veremos.

Dicho todo lo anterior, detengámonos un momento en dos de las características antes mencionadas que requieren un mayor análisis: los sujetos pasivos y las formas de comisión.

\section{MATERFAMILIAS Y JÓVENES PRAETEXTATI}

\section{Materfamilias}

No es empresa fácil reducir a una idea univoca el concepto de materfamilias ${ }^{25}$. Festo $^{26}$ la relata como una única mujer dentro de la familia que no está sometida a la potestad de un pater-de hecho, la palabra sería posterior a paterfamilia, creándose para oponerla a ésta-, no pudiendo ser aquella mujer que no tiene hijos, ni aquella que ha enviudado. Ulpiano ${ }^{27}$, a su vez, la caracteriza como una mujer, de cualquier edad, casada o viuda, ingenua o liberta, observadora de los boni mores. Ambas consideraciones en torno a la figura de la materfamilias parecen no encontrar puntos en común más allá de que la mater, en efecto, es mujer. Ahora bien, a nuestro juicio el problema es que materfamilias es un término marcado ${ }^{28}$ que tienen un significado contextual cuando se contrapone a su opuesto. Por ejemplo, vimos que Festo la opone a paterfamilias; para Elio Meliso, materfamilias es la que ha parido varias veces en oposición a matrona que es la que sólo ha parido una vez, en cambio para Gelio materfamilias es la mujer in manus, mientras que

${ }^{25}$ Fiori ha determinado diversos sentidos dados a la materfamilia: como mujer in manu, como mujer sui iuris, como mujer que vive honestamente observando los boni mores y como uxor. Las dos primeras formas parecen ser clásicas, mientras las dos últimas recorren la historia del Derecho romano. FIORI, Roberto, Materfamilias, en BIDR., 35-36/3 (Milano, 1993-1994), pp. 455 ss.; en cuanto a su indeterminación, vid. SALLER, Richard, Pater Familias, Mater Familias, and the Gendered Semantics of the Roman Household, en Classical Philology, 94/2 (Chicago, 1999), pp. 182-197.

${ }^{26}$ Festo, De verborum significatu, 11, 15.

${ }^{27}$ D. 50, 16, 46, 1 Ulp. 59 ad ed. "Matrem familias" accipere debemus eam, quae non inhoneste vixit: matrem enim familias a ceteris feminis mores discernunt atque separant. proinde nibil intererit, nupta sit an vidua, ingenua sit an libertina: nam neque nuptiae neque natales faciunt matrem familias, sed boni mores".

${ }^{28}$ Para Ferdinand de Sassure las palabras no valen por sí mismas sino en cuanto se oponen a otras. Bigot, Margot, Apuntes de lingüística antropológica (Bogotá, Centro Interdisciplinario de Ciencias Etnolingüísticas y Antropológico-sociales, 2010), pp. 43-44. 
la mater es aquella que se ha casado mientras subsista tal matrimonio, tenga o no hijos ${ }^{29}$ (¿Usus? ¿Sine manus? $)^{30}$, a su turno, Séneca se refiere a la materfamilias como mujer virtuosa, frente a las mujeres viciosas ${ }^{31}$, en fin, como vemos no es posible reducirla a una situación omnicomprensiva de todas, requiriendo de un contexto para saber, in concreto, cuando estamos hablando de una materfamilias.

Dicho ello, circunscribamos el análisis de la mater en relación a nuestro edicto. Así, para nosotros la mater que puede ser víctima de acosos corresponde a una mujer, libre, sin importar si ha contraído matrimonio, de cualquier edad y condición social ${ }^{32}$, y lo más relevante, celosa del pudor. Así, la protección no está dada a la mujer en cuanto mujer, sino a ella en cuanto a matrona: es la dignitas de la mujer y no el hecho de ser tal la que la hace merecedora de protección edictal ${ }^{33}$.

La pudicitia $^{34}$ es una diosa ${ }^{35}$, un modelo de vida (spectata pudicitia) ${ }^{36}$ y un elemento intrínseco de la idea de materfamilias ${ }^{37}$. La matrona romana en términos generales se estimaba como una mujer abnegada y obediente a su marido, cuyos signos de virtud pasan por no hablar demasiado - cabe recordar al a diosa Tácita- y no beber vino, pues, fuera de estimarse como delito durante el periodo arcaico, el vino desinhibe, lo que la llevaría a hablar, divertirse y comportarse en forma deshonrosa en público e incluso podría arrástrala al adulterio ${ }^{38}$. Recordemos que los ejemplos de mujeres virtuosas en Roma son Lucrecia ${ }^{39}$ y Virginia, ambos modelos de conservación de la pudicitia por sobre la propia vida, inclusive ${ }^{40}$. Tal

${ }^{29}$ NA. $18,6,4$.

${ }^{30}$ Sobre el particular véase Amunátegui Perelló, Carlos, El origen de los poderes del 'paterfamilias', II: el 'paterfamilias' y la 'manus', en REHJ., 21 (2007), pp. 52 ss.

${ }^{31}$ Ad. Helviam matrem de consolatione 17, 3-4.

${ }^{32}$ En contra, De Lapuerta Montoya, Dora, El elemento, cit. (n. 17), p. 240, para quien la mater debe pertenecer a una clase social alta, sobre la base de la protección vía comitem abducere, pues la costumbre de llevar acompañante (comes) era propia de las altas clases, la protección a los jóvenes praetextati cuya toga se reserva a estas esferas y la valoración objetiva de la exigencia de que las conductas lesivas sean adversus bonos mores. Tales argumentos no nos resultan del todo claro, pero volveremos sobre ellos cuando analicemos el comitem abducere.

${ }^{33} \mathrm{D} .47,10,1,2$ Ulp. 56 ad ed.- Omnemque iniuriam aut in corpus inferri aut ad dignitatem aut ad infamiam pertinere: in corpus fit, cum quis pulsatur: ad dignitatem, cum comes matronae abducitur: ad infamiam, cum pudicitia adtemptatur.

${ }^{34}$ Un muy interesante análisis en FusCO, Stefania, Edictum de adtemptata pudicitia, en Diritto e historia, 9 (Sassari, 2010), pp. 6-10.

${ }^{35}$ Plinio. "Nat. Hist. 2, 14, 1.- Quapropter effigiem dei formamque quaerer inbecillitatis humanae reor. Quisquis est deus, si modo est alius, et quacumque in parte, totus est sensus, totus visus, totus auditus, totus animae, totus animi, totus sui. Innumeros quidem credere atque etiam ex vitiis hominum, ut Pudicitiam, Concordiam, Mentem, Spem, Honorem, Clementiam, Fidem, aut, ut Democrito placuit, duos omnino, Poenam et Beneficium, maiorem ad socordiam accredit".

${ }^{36}$ Vid. López Güeto, Aurora, El derecho romano en femenino singular. Historias de mujeres (Madrid, Tecnos, 2018), p. 24.

${ }^{37}$ Bravo Bosch, María José, Mujeres y símbolos en la Roma republicana (Madrid, Dykinson, 2017), p. 205.

${ }^{38}$ López GÜETo, Aurora, El derecho, cit. (n. 36), pp. 31-33.

${ }^{39}$ Vid. Amunátegui Perelló, Carlos, Lucretia and the Historical System of Noxality, en RIDA., 55 (Milano, 2008), pp. 67 ss.

${ }^{40}$ López GÜETo, Aurora, El derecho, cit. (n. 36), p. 32. 
es el sentido del pudor de la mater romana que incluso tendrá cánones de vestimentas que adviertan, con el sólo verle, que ella es una materfamilias garante de los boni mores ${ }^{41}$. Es más, no vestir en forma apropiada hará al ofensor incurrir en menor culpa si le acosare ${ }^{42}$.

Tal pudicitia, a juicio de Cantarella, puede analizarse en cuanto a sustancia y en cuanto a forma. Sustancialmente, pudicitia es virginidad, lo que implicaría que la mujer matrona, educada para el matrimonio, no sea mancillada en su condición de virgo. Formalmente, la pudicitia es un problema de imagen, lo que justifica la necesidad de que la mater vista en forma apropiada ("la mujer del césar no sólo debe serlo, sino también parecerlo”, dice el refrán nacido del divorcio de César con Pompeya). Así las cosas, si la mujer lleva stola ha de presumirse mater, pues a las meretrices su uso les está vedado y a las adúlteras se les prohíbe tras su divorcio; a su turno, las esclavas usan ropas sencillas y las jóvenes solteras llevan toga praetexta, lo que de todas formas haría al ofensor incurrir en este delito. Por ende, sólo si la mujer lleva toga muliebris podría alegarse ignorancia de su condición de mater.

De Lapuerta apunta a que el edicto no exige que la mater sea especialmente virtuosa, sino que se sobrepase en términos objetivos el común sentido del pudor. Incluso, le parece excesivo que aun cuando Ulpiano mencione como vírgenes a las jóvenes praetextati se pueda siquiera pensar en un examen corporal de virginidad para hacer procedente la acción ${ }^{43}$. A nuestro juicio, la mención no está dada a la efectiva condición virginal de la joven, sino a la normal condición de la praetextata, pues si ella abandona tal toga cuando contrae matrimonio, imaginamos que ello es indicativo del consecuencial abandono de su condición; la protección está dada a la joven y no a la virgen, ocurriendo que lo normal y esperable es que ella lo sea.

\section{Jóvenes praetextati}

Los jóvenes praetextati son los mozos de cualquier sexo en edad de portar la toga praetexta, es decir, los varones que aún no han tomado la toga viril y las mujeres que no han contraído matrimonio. Según la tradición, uno de los hijos de Tarquino Prisco, siendo niño, en una guerra contra los sabinos luchó tan valerosamente contra sus enemigos que se le dio el honor de portar desde en-

\footnotetext{
${ }^{41}$ D. 34, 2, 23, 2 Ulp. 44 ad Sab.- "Vestimenta omnia aut virilia sunt aut puerilia aut muliebria aut communia aut familiarica. virilia sunt, quae ipsius patris familiae causa parata sunt, veluti togae tunicae palliola vestimenta stragula amfitapa et saga reliquaque similia. puerilia sunt, quae ad nullum alium usum pertinent nisi puerilem, veluti togae praetextae aliculae chlamydes pallia quae filiis nostris comparamus. muliebria sunt, quae matris familiae causa sunt comparata, quibus vir non facile uti potest sine vituperatione, veluti stolae pallia tunicae capitia zonae mitrae, quae magis capitis tegendi quam ornandi causa sunt comparata, plagulae penulae. communia sunt, quibus promiscui utitur mulier cum viro, veluti si eiusmodi penula palliumve est et reliqua huiusmodi, quibus sine reprehensione vel vir vel uxor utatur. familiarica sunt, quae ad familiam vestiendam parata sunt, sicuti saga tunicae penulae lintea vestimenta stragula et consimilia".

${ }^{42}$ D. 47, 10, 15, 15 Ulp. 77 ad ed.- "Si quis virgines appellasset, si tamen ancillari veste vestitas, minus peccare videtur: multo minus, si meretricia veste feminae, non matrum familiarum vestitae fuissent. si igitur non matronali habitu femina fuerit et quis eam appellavit vel ei comitem abduxit, iniuriarum tenetur".
}

${ }^{43}$ De Lapuerta Montoya, Dora, El elemento, cit. (n. 17), p. 239. 
tonces la toga de los magistrados ${ }^{44}$, costumbre que será heredada por los jóvenes nobles cuando Roma no sepa de monarquías ${ }^{45}$. Lleva razón De Lapuerta, en que la referencia a este tipo de toga es indicativa de la clase social de los jóvenes, lo cual secundamos, pues sólo las familias de las clases altas podrían permitirse que sus jóvenes usen esta toga, toda vez que ellas llevan una orla púrpura, cuyo tinte, el púrpura de tiro o púrpura fenicia, obtenido de la mucosa de un molusco en particular (murex brandaris), hacía de este color un verdadero lujo ${ }^{46}$. Dicho color, descubierto por el perro del dios fenicio Melqart (Heracles/Hércules), asociado con los reyes ${ }^{47}$, objeto de leyes suntuarias como la lex $O p p i a^{48}$, al decir de Plinio "hace majestuosa la niñez" 49 .

De esta forma y a diferencia de la materfamilias, en este caso la protección edictal sí se debe circunscribir a aquellos que portaban esta toga y, por ende, habrá diferencias por clases. A nuestro entender, al ser la situación de los hijos distinta a la de la mater, es posible establecer dichas diferencias. Recordemos que la protección no se da a la mujer por ser esa su condición, sino a su dignidad, que, en cierta medida, es una extensión de la dignidad del pater o el marido ${ }^{50}$. Lo mismo vale para los hijos ${ }^{51}$.

El acoso sexual contra los jóvenes no es extraño en la Roma republicana. Para el año 227 a. C. un tal Escatinio Capitolino, deseando al hijo de Claudio Marcelo trató de abordarle, lo cual no fue posible, tras lo cual Marcelo le denunció ante el pueblo (o Senado) siendo condenado a una suma de dinero ${ }^{52}$. No deja de resultar llamativo el hecho de que el nombre del ofensor corresponde al nombre de la ley que sancionaba el acoso y la pederastia de menores: la lex Scutia, que sanciona el stuprum cum puerum con penas pecuniarias. Aparentemente tendría dos problemas esta ley: las sanciones pecuniarias rara vez se imponían y no producían la suficiente coacción, y sólo sancionan la efectiva penetración, no el acoso ${ }^{53}$. De esta

${ }^{44}$ Macrobio, Saturnales 1, 6.

${ }^{45}$ De Lapuerta Montoya, Dora, El elemento, cit. (n. 17), p. 241.

${ }^{46}$ Fernández, Pilar, Púrpura. Del mercado al poder (Madrid, Uned, 2010), pp. 244 ss.

${ }^{47}$ Ibíd., pp. 38 ss.

${ }^{48}$ KüHnE, Viviana, La lex Oppia sumptuaria y el control sobre las mujeres, en RODRÍGUEZ López, Rosalía; Bravo Bosch, María José (eds.), Mulier. Algunas historias e instituciones de Derecho romano (Madrid, Dykinson, 2013), pp. 39 ss.

${ }^{49}$ Plinio, Nat. Hist, 9, 128.

${ }^{50}$ D. 47, 10, 15, 24 Ulp. 77 ad ed.- "Sponsum quoque ad iniuriarum actionem admittendum puto: etenim spectat ad contumeliam eius iniuria, quaecumque sponsae eius fiat".

${ }^{51}$ D. 47, 10, 1, 3 Ulp. 56 ad ed.- "Item aut per semet ipsum alicui fit iniuria aut per alias personas. per semet, cum directo ipsi cui patri familias vel matri familias fit iniuria: per alias, cum per consequentias fit, cum fit liberis meis vel servis meis vel uxori nuruive: spectat enim ad nos iniuria, quae in his fit, qui vel potestati nostrae vel affectui subiecti sint".

${ }^{52}$ Bio. Marcelo, 2, 5-8; Valerio Máximo, Fact. 6, 1, 7. Entre ambas narraciones hay pequeñas diferencias: la intervención del Senado o el pueblo para la determinación de la condena y la condición de edil curul de Marcelo. Lo que a nosotros nos llama la atención es la referencia la descripción del hijo en Plutarco como alguien reconocido por los ciudadanos por su prudencia y educación, y que él, siendo llevado ante el Senado, habría mostrado su deshonra y la referencia de Valerio a la pudicitia.

${ }^{53}$ Para conocer los problemas respecto a su nombre, contenido y fecha, véase CANTARELLA, 
manera, los acosos a los jóvenes continuaron aún con la lex Scutia, lo que habría hecho necesario el edictum de adtemptata pudicitia. Ahora bien, la lex Scutia no fue derogada, siendo mencionada luego por Cicerón.

Ahora bien, en cuanto al joven éste es mencionado como praetextati y no como puer según suele mencionarse en las fuentes, lo que a nuestro gusto destaca la importancia de tal calidad. Por ejemplo, el mismo Ulpiano obvia la calidad de los niños que juegan a la pelota a propósito de la lex Aquilia ${ }^{54}$, pues la importancia se encuentra en la c u l p a , mientras que para hablar de niños en general hace la alusión a puer ${ }^{5}$. Puer, según Paulo puede significar niños esclavos en general, niño en oposición a niña o aquellos en edad pueril ${ }^{56}$. Esta última parece coincidir con la edad de portar la praetexta $a^{57}$. Así, si el praetextati se encuentra en edad pueril, parece ser una condición particular que la distingue de los demás jóvenes, lo que lo hace merecedor de protección por el edicto.

Finalmente, y al igual que en el caso de la mater, el desuso de la toga praetexta por los jóvenes hace incurrir al ofensor en menor culpa a efectos de determinar la sanción por la injuria en caso de apellare o comiten abducere. Ahora bien, esta suerte de atenuante nos refuerza la idea de que praetextati hace una distinción entre los jóvenes. Si el acosador ve a una mujer que no lleva indumentaria de mater pensará "es meretriz o esclava" (=no es mater) mientras que si ve a un joven vestido inadecuadamente solo puede concluir "es púber" o "es un niño común" (= no es praetexti), pero si el primero lleva toga viril, entonces sólo queda concluir que es común, pues la conclusión "no es un joven" cae en el absurdo, pues ello está marcado por la edad.

\section{FORMAS COMISIVAS}

Las formas de acoso son tres según la reconstrucción propuesta: apartar a los acompañantes de una materfamilias o de jóvenes praetextati (comitem abducere); abordar a la mater o jóvenes diciendo palabras eróticas insinuantes a forma de cortejo (appellare); y seguirles insistentemente en forma discreta (adsectari).

Eva, Según natura, cit. (n. 11), pp. 146-149.

${ }^{54}$ D. 9, 2, 11, 10 Ulp. 18 ad ed.- "Item Mela scribit, si, cum pila quidam luderent, vehementius quis pila percussa in tonsoris manus eam deiecerit et sic servi, quem tonsor habebat, gula sit praecisa adiecto cultello: in quocumque eorum culpa sit, eum lege Aquilia teneri. Proculus in tonsore esse culpam: et sane si ibi tondebat, ubi ex consuetudine ludebatur vel ubi transitus frequens erat, est quod ei imputetur: quamvis nec illud male dicatur, si in loco periculoso sellam habenti tonsori se quis commiserit, ipsum de se queri debere".

${ }^{55}$ D. 50, 5, 2, 8 Ulp. 3 opin.- "Qui pueros primas litteras docent, inmunitatem a civilibus muneribus non habent: sed ne cui eorum id quod supra vires sit indicatur, ad praesidis religionem pertinet, sive in civitatibus sive in vicis primas litteras magistri doceant".

${ }^{56}$ D. 50, 16, 204, pr Paul. 2 epit.- "Alf.. 'pueri' appellatio tres significationes habet: unam, cum omnes servos pueros appellaremus: alteram, cum puerum contrario nomine puellae diceremus: tertiam, cum aetatem puerilem demonstraremus".

${ }^{57}$ Tácito, Annales, 12, 41.- "[...] Britannicus in praetexta, Nero triumphali veste travecti sunt: spectaret populus hunc decore imperatorio, illum puerili habitu, ac perinde fortunam utriusque praesumeret". 


\section{Comitem abducere}

Siguiendo el orden dado por la reconstrucción edictal de Lenel revisaremos primero el denominado comitem abducere, que según lo dicho por Ulpiano ${ }^{58}$ consiste en atentados contra el pudor de la mater o pretextati cuando se aparta a su acompañante. Dijimos que a juicio de De Lapuerta ${ }^{59}$, la existencia de dichos acompañantes acusa el status de la víctima, puesto que sólo los jóvenes y las matronas de altas clases los llevan para protegerles y apartar a la muchedumbre, incluso señala que las mujeres libres de la plebe no iban acompañas de comes, por lo que no sería a su respecto posible el comitem abducere. Sin embargo, no nos queda suficientemente claro que ello sea necesariamente así.

La autora funda su argumento en un fragmento de Danae $e^{60}$ del poeta arcaico Gneo Naevio, lo cual, si bien tiene el mérito de ser una obra muy próxima a la fecha en que posiblemente se dio el edicto general y un poco más lejana al de adtemptata pudicitia, fue escrita justo en un periodo de inflexión en la historia del delito y de Roma. Si tomamos en consideración lo dicho por Gelio ${ }^{61}$, Naevio participó de la Primera Guerra Púnica, aunque Licinio afirma que comenzó a componer tras la Segunda. Ahora bien, sabemos que para el año 231 a. C. habría presentado su primera obra teatral ${ }^{62}$, es decir, quince años antes de lo dicho por Licinio, lo que guarda relación con la incardinación dada por Gelio ${ }^{63}$. Por ende, la obra es a lo menos cien años anterior al edicto de adtemptata pudicitia, lo cual en general no es mucho para la evolución de ciertas instituciones jurídicas, salvo en ciertos periodos, como éste donde la sociedad que se pretende reflejar a través de la fuente puede no ser la misma que se comenta. No debemos pasar por alto el hecho de que esta tragedia corresponde a una adaptación romana de "Las troyanas" de Eurípides, donde las mujeres son, en efecto, parte de la corte de Príamo, lo que explicaría que Danae sea una princesa, hija de Acrisio, rey de Argos, lo que podría hacer pensar en que sólo las mujeres aristócratas se hicieran escoltar.

En cuanto al fragmento, este dice "desubito famam tollunt si quuam solam videre in via", es decir, que la mujer pierde su fama si es vista sola en la calle, de lo cual no es dable per se concluir que el comes sólo acompaña a una mujer de clase alta. Por lo demás, tampoco demuestra que una mujer de la plebe no pueda llevar comes, sino que la mujer que es vista sola en la calle pierde su fama ${ }^{64}$, lo que

${ }^{58}$ D. 47, 10, 15, 16-18.- "Comitem accipere debemus eum, qui comitetur et sequatur et (ut ait Labeo) sive liberum sive servum sive masculum sive feminam: et ita comitem Labeo definit "qui frequentandi cuiusque causa ut sequeretur destinatus in publico privatove abductus fuerit". inter comites utique et paedagogi erunt. (17) Abduxisse videtur, ut Labeo ait, non qui abducere comitem coepit, sed qui perfecit, ut comes cum eo non esset. (18) Abduxisse autem non tantum is videtur, qui per vim abduxit, verum is quoque, qui persuasit comiti, ut eam desereret".

${ }^{59}$ Vid. De Lapuerta Montoya, Dora, El elemento, cit. (n. 17), p. 240. En igual sentido, Cantarella Eva, Según natura, cit. (n. 8), p. 155.

${ }^{60}$ GNeo NaEvio, Danae, fragmento 6.

${ }^{61}$ NA. $17,21,45$.

${ }^{62}$ Varrón, De poetis, fragmento 45.

${ }^{63}$ NA. 17, 21, 46.

${ }^{64}$ Posiblemente, de ser confundida con prostituta. Cfr. Cistellaria, 331.- "intro abeo, nam meretricem astare in via solam prostituti sanest", Resulta llamativo que, quien se decide a 
guarda relación con la pudicitia. Así, en resguardo de tal pudor, se hace acompañar, pero ¿por quién? Creemos que es importante determinar el significado de comes.

A propósito de nuestro edicto se suele afirmar que comes es un suerte de escolta que acompaña a las materfamilias o los jóvenes en edad de portar toga praetexta ${ }^{65}$. Las palabras comitiva, comité, compañía, tienen su raíz aquí. Sin embargo, un estudio etimológico de la palabra nos hace resistirnos a la idea de que comes se reduzca a un particular acompañante, sino que más bien parece una palabra con un sentido del todo amplio, incluso polisémico, que nos aparta de la idea de un acompañante-escolta.

Para Ernout y Meillet ${ }^{66}$, comes se entiende como la compañía en la marcha, en relación a la compañía militar de eques (los compañeros de caballería), derivando por influencia de pedes en acompañamiento al caminar. Señalan además que los comes frecuentemente acompañaban a un superior, como un procónsul, y en época imperial, al emperador, pero que, en un sentido lato, se entiende como acompanante. Además, señalan que la $e$ en lugar de $i$ (comis) se explica por la influencia de equites. A su turno, el Oxford Latin Dictionary ${ }^{67}$, agrega a lo ya dicho, que comes puede estar referido a acompañante (sea persona o cosa), a compañero, amigo o camarada, a menudo de inferior rango o del mismo nivel (como en el contrato de sociedad o compañía), a un siervo o trabajador, o a parte del consilium de un cónsul o líder militar. A su turno, comis, es una característica de algo o alguien amable, afable o gracioso (cómico), de buen gusto, elegante o culto, derivado de cosmis. De todas formas, tal adjetivo, puede estar referido a amigos, amantes, a la mujer, escoltas, entre otros, y de la cual derivan palabras tales como comiter o comitia. Cosmis es una palabra del latín arcaico que podemos ver en el vaso de Duenos $^{68}$, referido a una sponsalia, donde la mujer debe resultar agradable (cosmis/ comis) al esposo (ted), so pretexto de ser devuelta su gens. Como vemos, comis resulta ser un adjetivo por lo que alguien debe resultar agradable, gracioso, etc. ¿Quién? el o la compañera.

Si revisamos las comedias de Plauto, comes aparece referida en Amphitruo ${ }^{69}$ y en Mercator $^{70}$ sólo tres veces. Particularmente, en Mercator (2, 3, 403-410) el

entrar es una cortesana (meretriz), completamente alejado a la idea de la virtud femenina, y presumiblemente, carente de abolengo alguno.

${ }^{65}$ Cantarella Eva, Según natura, cit. (n. 11), p. 155.

${ }^{66}$ Ernout, Alfred; MeIllet, Alfred, Dictionnaire etymologique de la langue latine. Histoire $\operatorname{des}_{\text {mots }}{ }^{3}$ (1932, París, Librairie C. Klincksieck, 1951), pp. 135-136.

${ }^{67}$ Oxford Latin Dictionary, pp. 359-360.

68 "Iurat deos qui me mittit: ni apud te comis virgo sit, adstet nobis. (Iurat) opi et utilitati pangi vobis. Bonus me fecit in bonum; enim bono ne e me malus stet". MarCo Simón, Francisco; Fontana, Gonzalo, Sponsio matrimonial en la Roma arcaica: el vaso de Duenos, en RIDA., 43 (Bruxelles, 1996), pp. 213-268.

${ }^{69}$ Amphitruo 2, 2, 635.- "ALCVMENA Satin parva res est voluptatum in vita atque in aetate agunda praequam quod molestum est? ita cuique comparatum est in aetate hominum; ita divis est placitum, voluptatem ut maeror comes consequatur: quin incommodi plus malique ilico adsit, boni si optigit quid".

${ }^{70}$ Mercator 5, 2, 850.- “CHAR. Apparatus sum ut videtis: abicio superbiam; egomet mihi comes, calator, equos, agaso, armiger, egomet sum mihi imperator, idem egomet mihi oboedio, egomet mihi fero quod usust. o Cupido, quantus es. nam tu quemvis confidentem facile tuis factis facis, eundem 
comes será una esclava que no supondría defensa alguna frente a los acosos. De hecho, la negativa a que la esclava (muy bella, por cierto) sea la acompañante de una mater se da justamente porque puede incitar al acoso, lo que avergonzaría a la matrona. De esta manera, para nosotros comes es un acompañante o un compañero en sentido amplio, pudiendo tratarse de una comitiva como los que solían llevar las personas importantes, $-\mathrm{y}$ presumiblemente, las materfamilias aristocráticas- como de amigos, esclavos, escoltas o inclusive, el marido de una mater que no pertenezca a la aristocracia, o sus hijos. Respecto a estos últimos recordemos el sentido comis de alguien agradable o gracioso, que en el caso de la mater no puede ser sino alguien de su círculo más íntimo, pues la dignitas de ella le impediría hacerse acompañar de cualquiera. Ulpiano, siguiendo a Labeón, define al acompañante como el que sigue y acompaña, sea libre, esclavo, hombre o mujer. Es decir, por razón de sexo o por razón de status, el acompañante puede ser cualquiera. Más restrictivo es Labeón quien habla del que está destinado a seguirles (¿esclavo? ¿cliente? ¿ubi Gaio ego Gaia?) ${ }^{71}$.

Ahora bien, ¿qué debemos entender por alta clase? ¿̨mujeres patricias? ¿̨mujeres adineradas? La verdad, es que ni una u otra distinción satisface el problema, pues las fuentes pasan en silencio la calidad de la mujer. Ya desde el siglo III a. C., la diferencia de clases entre patricios y plebeyos será un rancio abolengo sin mayor importancia. La lex Hortensia ha sometido a ambos a las mismas reglas y la lex Canuleia ha abolido la prohibición de celebrar matrimonios entre tales y cuáles. En cuanto a la injuria -y, por tanto, a los edictos- desde las XII Tablas ha existido una voluntad isonómica en este cuerpo normativo. Pensar en que la iniuria que otrora imponía el talión sin distinción, trescientos años después volvería a establecer diferencias es una involución legislativa. Es más, al final de la tercera guerra samnita nacerá un culto a la pudicitiae plebeiae ${ }^{72}$, lo que refuerza aún más la idea de que no pude existir distinción patricio-plebeya en la consideración de

ex confidente actutum diffidentem denuo; Mercator 2, 3, 403-410.- DEM. Labefacto paulatim. verum quod praeterii dicere, neque illa matrem satis honeste tuam sequi poterit comes, neque sinam. CHAR. Qui vero? DEM. Quia illa forma matrem familias flagitium sit si sequatur; quando incedat per vias, contemplent, conspiciant omnes, nutent, nictent, sibilent, vellicent, vocent, molesti sint; occentent ostium: impleantur elegeorum meae fores carbonibus. atque, ut nunc sunt maledicentes homines, uxori meae mihique obiectent lenocinium facere. nam quid eost opus?".

${ }^{71}$ D. 47, 10, 15, 16 Ulp. 77 ad ed.- "Comitem accipere debemus eum, qui comitetur et sequatur et (ut ait Labeo) sive liberum sive servum sive masculum sive feminam: et ita comitem Labeo definit 'qui frequentandi cuiusque causa ut sequeretur destinatus in publico privatove abductus fuerit'. inter comites utique et paedagogi erunt".

${ }^{72}$ Tito Livio, Ab. urb. 10, 23, 3-10 “[...]'hanc ego aram' inquit 'Pudicitiae Plebeiae dedico; vosque hortor ut, quod certamen virtutis viros in hac civitate tenet, hoc pudicitiae inter matronas sit detisque operam ut haec ara quam illa, si quid potest, sanctius et a castioribus coli dicatur'. Eodem ferme ritu et haec ara quo illa antiquior culta est, ut nulla nisi spectatae pudicitiae matrona et quae uni viro nupta fuisset ius sacrificandi haberet; volgata dein religio a pollutis, nec matronis solum sed omnis ordinis feminis, postremo in oblivionem venit". Hay tres cosas que llaman poderosamente la atención: un culto a la Pudicitiae plebeiae junto a la Pudicitia patricia, el uso por Livio de la voz matrona en referencia a mujeres plebeyas, y el hecho de que haya caído en el olvido este culto por la llegada de mujeres de toda clase, lo que opone a la mater plebeya con las que no son mater: meretrices y prostitutas, al igual que la noción mater del edicto. 
mater. Ahora, si el fundamento está en la capacidad económica, los plebeyos no eran para nada los menesterosos de la ciudad ${ }^{73} \mathrm{y}$, de hecho, financiaron las guerras púnicas. Es más, la lex Oppia que prohibía a las mujeres exhibir sus riquezas no se refería a las patricias, a tal punto, que mujeres de ambas clases se volcaron a las calles a protestar contra ella ${ }^{74}$.

Tampoco el hecho de que el edicto otorgue protección a los praetextati nos parece que pueda hacernos concluir que la mater debe pertenecer a una determinada clase social. Como sostuvimos, la condición de la matrona romana no es la misma que la de los hijos de familia, aun cuando ésta se encuentre loco filia dentro del grupo familiar. Además, en un derecho en constante evolución como el arcaico es posible encontrar situaciones que, a nuestros ojos, no responden a un criterio lógico ¿̨Por qué sancionar la fractura de un hueso de un esclavo en las XII Tablas y no la rotura de un miembro? Luego, tampoco la idea de que las mujeres de la plebe no fueran a acudir ante el pretor por atentados impúdicos nos puede hacer inclinar a pensar que este edicto protege únicamente a mujeres patricias. Fuera de que ello supone una conjetura, vimos que las plebeyas tenían su propio culto a la Pudicitiae Plebeiae. Dicho ello, para nosotros, al menos en lo que respecta a la materfamilias, no es posible afirmar un impedimento para que las mujeres de cualquier condición sean protegidas por este edicto.

A los acompañantes se les puede apartar por medio de la fuerza o la persuasión y en ambos casos se estará atentando contra el pudor de la mater o los praetextis ${ }^{75}$. Recordemos aquella célebre escena de la serie Roma de HBO, donde, previo a su muerte, César es escoltado a la curia por Lucio Voreno, quien es interceptado en el camino y advertido de que su mujer le había sido infiel. Éste, absorto de ira, abandona la escolta y se dirige a su casa. Siendo justos con Voreno, su presencia no habría evitado el desenlace. Ahora, obviando el hecho de que César no es ni mater ni un niño, el ejemplo resulta ilustrativo. Así, no sólo se aparta al acompañante cuando se le empuja, se le retiene, cuando el acosador se interpone entre el sujeto pasivo y el comes, sino también cuando se le intimida, engaña, o soborna, entre otras muchas otras formas de quitar al acompañante ${ }^{76}$.

Como señala De Lapuerta ${ }^{77}$, lo que compartimos, a diferencia de las otras dos formas de comisión del ilícito, parece que no es necesario al momento de la litis aestimatio, que el juez analice si se ha sobrepasado el límite objetivo dado por los boni mores, ya que el mero hecho de apartar al acompañante sería un atentado al pudor.

${ }^{73}$ López Güeto, Aurora, El derecho, cit. (n. 32), p. 24.

${ }^{74}$ Tito Livio, $A b$. Urb. 34. 1.- No hace distinción de mujeres de ninguna condición.

${ }^{75}$ D. 47, 10, 15, 17-18 Ulp. 77 ad ed.- "Abduxisse videtur, ut Labeo ait, non qui abducere comitem coepit, sed qui perfecit, ut comes cum eo non esset. (18) Abduxisse autem non tantum is videtur, qui per vim abduxit, verum is quoque, qui persuasit comiti, ut eam desereret".

${ }^{76}$ Vid. Bravo Bosch, María José, Algunas consideraciones sobre el edictum de adtemptata pudicitia, en Dereito, 5/2 (Santiago de Compostela, 1996), p. 50.

77 Vid. De Lapuerta Montoya, Dora, El elemento, cit. (n. 17), p. 242. 


\section{Appellare y adsectari}

Appellare, nos señala Ulpiano, es "atentar con dulces palabras la honestidad de alguien" "78, el cual tiene para el jurista sentido particular. Desde luego y como se refleja en el texto en comento, apelar no es insultar, ya que ello sería sin más una forma de injuria. Appellare es usar palabras blandas, que incluso alguno podría calificar de agradables -argumento con el cual hasta hoy se pretende defender al acoso- pues el acento no debe ponerse en si produce o no subjetivamente ofensa, o si se hizo con la intención de seducir o de ofender, puesto que el parámetro se encuentra en los boni mores: en sobrepasar aquello que la sociedad entiende como buenas costumbres. Respecto a nuestro edicto, adversus bonos mores no se encuentra definido, pero sí lo está a propósito del edicto de convicio. Tal edicto es anterior al nuestro, por lo cual no es descabellado suponer que los boni mores y la forma de atentar contra ellos, eran ya conocidos por los romanos, por lo que no era necesario volver a señalarlos. Labeón sostiene que adversus bonos mores se analiza no respecto del ofensor, sino del común entendimiento de la ciudad ${ }^{79}$. Agreguemos que tampoco ha de estimarse respecto al ofendido, puesto que es una consideración objetiva. De esta forma, basta que el pyropo ${ }^{80}$ sea adversus bonus mores para que configure el ilícito con independencia de si ha producido efectivamente ofensa, indiferencia, risa o halago del receptor. Así las cosas, Ulpiano se preocupa de explicitar que appellare no es una forma de convicium $^{81}$ sino de adversus bonos mores, por lo tanto, las palabras torpes no se sancionan por este edicto $^{82}$. Incluso y para aún mayor precisión del concepto, el jurista distingue apellare de adsectari, es decir, piropear de seguir ${ }^{83}$. Recordemos que, al igual que frente al comes abducere, el sujeto activo puede alegar ignorancia de la condición del pasivo, toda vez que éste va mal vestido.

Adsectari, a su vez, implica seguir tácitamente y con frecuencia ya que es la asidua frecuencia la que constituye una cierta infamia ${ }^{84}$. Por ende, no hay atentado impúdico por el mero hecho de seguir a un praetextatus o a una mater, sino que debe hacerse de tal forma que se pueda tener por infamante, por ejemplo, parapetándose en los muros, escondiéndose tras la muchedumbre, acelerando

${ }^{78}$ D. 47, 10, 15, 20 Ulp. 77 ad ed.- "Appellare est blanda oratione alterius pudicitiam adtemptare: hoc enim non est convicium, sed adversus bonos mores adtemptare".

${ }^{79}$ D. 47, 10, 15, 6 Ulp. 77 ad ed.- "Idem ait "adversus bonos mores" sic accipiendum non eius qui fecit, sed generaliter accipiendum adversus bonos mores huius civitati".

80 "Fuego rojo" que puede entenderse como "fuego en la cara" (pyro/fuego-ops/cara) o enrojecimiento, que refuerza la idea de atentado impúdico.

${ }^{81}$ No nos referiremos al Edicto de convicium aquí, pero en resumidas cuentas consiste en vociferaciones en público para deshonrar. vid. MANFredini, Arrigo, La diffamazione verbale, cit. (n. 12), pp. 49 ss.

${ }^{82}$ D. 47, 10, 15, 21 Ulp. 77 ad ed.- "Qui turpibus verbis utitur, non temptat pudicitiam, sed iniuriarum tenetur".

${ }^{83}$ D. 47, 10, 15, 22 Ulp. 77 ad ed.- "Aliud est appellare, aliud adsectari: appellat enim, qui sermone pudicitiam adtemptat, adsectatur, qui tacitus frequenter sequitur: adsiduo enim frequentia quasi praebet nonnullam infamiam".

${ }^{84}$ D. 47, 10, 15, 22 Ulp. 77 ad ed.- "[...] adsectatur, qui tacitus frequenter sequitur: adsiduo enim frequentia quasi praebet nonnullam infamiam". 
el paso, etc. Además, ello debe ser con frecuencia. El mismo hecho de que el seguimiento sea frecuente, creemos que sirve como fundamento para sostener que no podría alegarse por el ofensor que desconocía la condición de mater o praetextus, pues, si le ha seguido con frecuencia es dable pensar que ha reparado en quien está siguiendo.

Ahora bien, sostuvimos que comitem abducere se comete por el sólo hecho de apartar al acompañante. Sin embargo, appellare y adsectari requieren de una conducta dolosa, donde el ofensor acose representándose que su actuar está atentando contra el pudor de la mater o del praetextatus. De este modo, Ulpiano establece que el pyropo o el seguimiento frecuente hechos en broma o en un sentido honesto no dan acción (actio iniuriarum aestimatoria) contra el presunto ofensor. Así, si uno ha seguido por varios días a una mater para transmitirle un mensaje privado, evidentemente no comete atentado al pudor, aun cuando la mater, en efecto, se pueda haber sentido acosada. Sin embargo y en cuanto a las palabras dichas por broma, si bien pueden no dar acción por el edicto especial de adtemptata pudicitia, nada obsta a que se den por el edictum generale, ya que, si bien una broma puede que no vulnere la pudicitia en términos objetivos, subjetivamente bien podría afectar al honor.

Finalmente, cabe referirse a la sanción. Aun cuando la reconstrucción de Lenel nada diga a este respecto, las fuentes revelan que adtemptata pudicitia es una forma de iniuria (edictal) y, por ende, la condena será pecuniaria y aestimatoria cum taxatione, teniendo como base para la litis aestimatio, lo que el juez considere bonum et aequum, debiendo ponderarse la contravención a las buenas costumbres por alguna de las conductas lesivas descritas anteriormente (comitem abducere, appellare, adsectari) contra cualquiera de los sujetos pasivos. Con todo, cuando alguno de los requisitos que hacen procedenteeste edicto falte, aun podrá quedar a salvo la acción general por injurias, como en el caso de error respecto a la condición de la persona respecto de apellare o adsectari o de convicium cuando se usen palabras torpes o insultos.

\section{EN CONCLUSIÓN}

De este modo y para concluir, volviendo a las ordenanzas municipales y a la reforma al Código Penal con las que comenzamos esta exposición, vemos cómo en el edicto de adtempata pudicitia encontramos un correlato de ello, donde sólo ha cambiado el fundamento de la protección, (ampliándolo): hoy se protege a la persona en cuanto tal y no respecto a su rol en la sociedad, pero las conductas punibles y la forma de sancionarlas no han variado. Quizás lo que más resalta del edicto es su requisito esencial: que ello sea adversus bonos mores, de este modo, creemos que dudar si el derecho está llamado a regular estas conductas no es dable, sino que debemos determinar como sociedad qué es lo que estamos dispuestos a tolerar, cuáles son nuestros bonos mores, y tras eso vendrá el campo de acción de la norma. 


\section{BiBLIOGRAFÍA}

Amunátegui, Carlos, El origen de los poderes del 'paterfamilias', II: el 'paterfamilias' y la 'manus', en REHJ., 21 (2007), pp. 51-163.

-Lucretia and the Historical System of Noxality, en RIDA., 55 (Bruxelles, 2008), pp. 67-81.

- Historia social, politica y jurídica de Roma (Santiago de Chile, Abeledo Perrot, 2011).

- Market Economic in the Middle Republic, en ZSS., 101 (Weimar, 2015), pp. 452-458.

ApPleton, Charles, Notre enseignement du droit romain, ses ennemis et ses défauts, en

Collinet, Paul; De Visscher, Fernand (eds.), Mélanges de droit romain dédiés a Georges Cornil (Paris, Sirey, 1926), I, pp. 43-79.

BINDING, Karl, Rechtsvergleichende Vermutungen zu membrum ruptum, os fractum und injuria der Lex XII Tabularum, en ZSS., 40/1 (Weimar, 1919), pp. 106-112.

BigOT, Margot, Apuntes de lingüistica antropológica (Bogotá, Centro Interdisciplinario de Ciencias Etnolingüísticas y Antropológico-sociales, 2010).

BIRKs, Peter, The early history of iniuria, en TR., 37 (Groningen - Bruxelles - La Haye, 1969), pp. 163-208.

Bravo Bosch, María José, Sobre el origen histórico del edicto de convicio, en Revista General de Derecho Romano, 23 (1983), pp. 1-45.

- Algunas consideraciones sobre el edictum de adtemptata pudicitia, en Dereito, 5/2 (Santiago de Compostela, 1996), pp. 41-53.

- La injuria verbal colectiva (Madrid, Dykinson, 2007).

- A propósito de la protección del honor de la persona, en Revista Jurídica Universidad Autónoma de Madrid, 16/2 (Madrid, 2007), pp. 29-54.

Cannata, Carlo Augusto, Sul texto della Lex Aquilia e la sua portata originaria, en VACCA, Letizia (ed.), Carlo Augusto Cannata. Scriti Scelti (Turín, G. Giappichelli Editore, 2012), II, pp. 153-183.

Cantarella, Eva, Según natura. La bisexualidad en el mundo antiguo (1988, Madrid, trad. cast., Akai, 1991).

Carvajal, Patricio Ignacio, La función de la pena por la 'iniuria' en la Ley de las XII Tablas, en REHJ., 35 (2013), pp. 151-178.

Carvajal, Patricio Ignacio, La iniuria en las XII tablas. Cuestiones filológicas, históricas y dogmáticas, en Mondaca Miranda, Alexis; Aedo Barrena, Cristián (eds.), Nuevos horizontes del derecho privado (Santiago de Chile, Librotecnia, 2013), pp. 57-120.

Cursi, Maria Floriana, Iniuria cum damno. Antigiuridicità e colpevolezza nella storia del danno aquiliano (Milano, Giuffrè, 2002).

CunsI, Maria Floriana, Danno e responsabilità extracontratratuale nella storia del diritto privato (Napoli, Jovene, 2010).

Da Nobrega, Vandick, La "iniuria" dans la loi des XII tables, en Romanitas, 8 (1967), pp. 250-279.

DAUBE, David, Ne quid infamandi causa fiat. The roman law of defamation, en Collected Studies in Roman Law (Frankfurt, V. Klostermann, 1991), pp. 465-500.

De Lapuerta Montoya, Dora, El elemento subjetivo en el edictum de adtemptata pudicitia: La contravención de los boni mores como requisito esencial para la existencia de responsabilidad, en Anuario da Facultade Dereito da Universidade da Coruña, 2 (1998), pp. 237-252.

-Estudio sobre el edictum de adtemptata pudicitia (Madrid, Tirant Lo Blanch, 1999). 
De Martino, Francesco, Storia economica di Roma antica (Florencia, La Nuova Italia Editrice, 1979), 2 vols.

Di PaOla, Santi, la genesi storica del delitto di 'iniuria’, en Annali del Seminario Giuridico dell'Università di Catania, 1 (Catania, 1946-1947), pp. 265-294.

ERnout, Alfred; MeILlET, Alfred, Dictionnaire etymologique de la langue latine. Histoire $\operatorname{des}_{\operatorname{mots}^{3}}$ (1932, París, Librairie C. Klincksieck, 1951).

Escutia Romero, Raquel, La difamación pública en derecho romano, en Revista Jurídica Universidad Autónoma de Madrid, 22/2 (Madrid, 2010), pp. 64-104.

Fernández Uriel, Pilar, Púrpura. Del mercado al poder (Madrid, Uned, 2010).

FIORI, Roberto, Materfamilias, en BIDR., 35-36, 3 (Milano, 1993-1994), pp. 455-498.

Forsythe, Gary, A Critical History of Early Rome (Berkeley, University of California Press, 2005).

Fusco, Stefania, Edictum de adtemptata pudicitia, en Diritto e historia, 9 (Sassari, 2010), pp. 6-10.

Guerrero Lebrón, Macarena, La injuria indirecta en derecho romano (Madrid, Dykinson, 2005).

GuZMÁn Brito, Alejandro, Derecho privado romano² (1996, Santiago de Chile, Legal Publishing-Thomson Reuters, 2013), 2 vols.

Hagemann, Matthias, Iniuria. Von den XII-Tafeln bis zur justinianischen Kodifikation (Köln - Weimar - Wien, Böhlau, 1998).

Huvelin, Paul, La notion de l'iniuria dans le très ancien droit romain (Lyon, A. Rey, imprimeur-éditeur, 1903).

IHerING, Rudolph, Actio injuriarum. Des lésions injurieuses en droit romain let en droit français] (Paris, Chevalier-Marescq \& Cie. Éditeurs, 1888).

KASER, Max, Das römische zivilprozessrecht (München, C. H. Beck'sche verlagsbuchhandlung, 1996).

KÜHNE, Viviana, La lex Oppia sumptuaria y el control sobre las mujeres, en RODRíGUEZ López, Rosalía; Bravo Bosch, María José, Mulier. Algunas historias e instituciones de derecho romano (Madrid, Dykinson, 2013), pp. 39-52.

Lenel, Otto, Das Edictum Perpetuum. Ein Versuch zu seiner Wiederherstellung ${ }^{3}$ (1883, Lepizig, Tauchnitz, 1927).

López GÜeto, Aurora, El derecho romano en femenino singular. Historias de mujeres (Madrid, Tecnos, 2018).

LuZZATTO, Giuseppe, Per un’ipoesi sulle origini e la natura delle obbligazioni romane (Milano, Giuffrè, 1934).

Manfredini, Arrigo, Contributi allo studio dell'iniuria in età repubblicana (Milano, Giuffrè, 1977).

—La diffamazione verbale nel diritto romano (Milano, Giuffrè, 1979).

Marco Simón, Francisco, Fontana, Gonzalo, Sponsio matrimonial en la Roma arcaica: el vaso de Duenos, en RIDA., 43 (Bruxelles, 1996), pp. 213-268.

Miglietta, Massimo, Le norme di diritto criminale, en Cursi, Maria Floriana (ed.), XII Tabulae. Testo e commento (Nápoles, Edizioni Scientifiche Italiane, 2018), II, pp. 479-559.

Mommsen, Theodor, Römischen Strafrecht (Leipzig, Verlag von Duncker \& Humblot, 1899), 4 vols.

Perozzi, Silvio, Istituzioni di Dirito romano, en CAPOGrossi, Luigi (ed.), Istituzioni di Dirito romano. Ristampa dell'edizione del 1928² (1928, reimp., Roma, 1963), II. 
Plescia, Joseph, The development of 'iniuria', en Labeo, 23 (Napoli, 1977), pp. 271-282. PÓlaY, Elemér, Iniuria types in Roman law (Budapest, Akadémiai Kiadó, 1986).

Pugliese, Giovanni, Studi sulliniuria. (Milano, Giuffrè, 1940).

RodGer, Alan, Introducing “iniuria”, en TR.., 59 (Groningen - Bruxelles - La Haye, 1991), pp. 1-11.

Saller, Richard, Pater Familias, Mater Familias, and the Gendered Semantics of the Roman Household, en Classical Philology, 94/2 (Chicago, 1999), pp. 182-197.

Santa Cruz, José; D'Ors, Álvaro, A propósito de los edictos especiales 'De iniuriis', en AHDE., 49 (Madrid, 1979), pp. 653-659.

SCHEILDEL, Walter et al., The Cambridge Companion to the Roman Economy (Londres, Cambridge University Press, 2012).

Schulz, Fritz, Derecho romano clásico (trad. cast., Barcelona, Bosch, 1960).

SIMON, Dietrich, Begriff und Tatbestand der 'iniuria' im altrömischen Recht, en ZSS., 82 (Weimar, 1965), pp. 132-187.

Voigt, Moritz, Die XII Tafeln Geschichte und System des Civil- und Criminal-Rechtes, wie -Processes der XII Tafeln nebst deren Fragmenten (Leipzig, Verlag von A. G. Liebeskind, 1883), 2 vols.

Von LÜвтоw, Ulrich, Zum römischen Injurienrecht, en Labeo, 15 (Milano, 1969), pp. 131-167.

Watson, Alan, Personal Injuries in the XII Tables, en TR., 43 (Groningen - Bruxelles - La Haye, 1975), pp. 213-222.

Wittmann, Roland, Die Körperverletzung an freien im klassischen römischen Recht (München, Beck, 1972).

Zimmermann, Reinhard, The Law of Obligations. Roman Foundations of the Civilian Tradition (Oxford, Oxford University Press, 1996). 